\title{
An incidental finding of a vegetative foreign body in left main bronchus in a child presented as wheeze associated respiratory tract infection
}

\author{
Balaji.M.D', Venkatamurthy M. $^{2}$, Naresh S. ${ }^{3}$ \\ ${ }^{1}$ Dr. Balaji. M.D. Professor, ${ }^{2}$ Dr. Venkatamurthy. M., Professor, ${ }^{3}$ Dr. S. Naresh, Resident, all authors are \\ affiliated with Department of Pediatrics, Adichunchanagiri Institute of Medical Sciences, B.G. Nagar- 571448 \\ Karnataka, India.
}

Address for Correspondence: Dr. S. Naresh, Email: nareshrajambbs@gmail.com

\begin{abstract}
Foreign body aspiration is an important cause of pediatric morbidity and mortality, particularly in children between the age of 6 months and five years. It is potentially life threatening event and may also cause chronic lung injury, if not properly managed. Foreign bodies may cause chronic pulmonary infections, bronchiectasis and lung abscess. An early diagnosis and management of the patient with an inhaled foreign body offers a diagnostic challenge to the treating pediatrician. We report a case of incidental foreign body in a 3year old child presented with recurrent episodes of wheeze associated respiratory tract infections. Wheeze was associated with persistent cough and dyspnea with nocturnal awakening.
\end{abstract}

Key words: Foreign body, Rigid bronchoscopy, peanuts

\section{Introduction}

Foreign body aspiration in children is most common especially those below the age of 3 years [1]. Foreign body causes significant airway occlusion it may lead to asphyxia and it is unfortunately a leading cause of death in childhood [2]. However, aspiration of foreign body more often presents with a history of an initial episode of choking and coughing with subsequent respiratory symptoms [1,3]. These include cough, wheeze, stridor, or pneumonia. The most common lung sign is decreased breath sounds or abnormal breath sounds $[1,4]$. In children food items are the most commonly inhaled foreign bodies and peanuts being the most common [4].

\section{Case Report}

A 3 year old boy bought with complaints of cough since 3 weeks with occasional noisy breathing at nights, with no other complaints. There is no history suggestive of choking, shortness of breath. On examination there is bilateral air entry with markedly reduced breath sounds on left side of chest with hyper resonance on percussion, and X-ray revealed emphysematous lung with hyper inflated lung fields on left side.

Patient was hospitalized and advised for computed tomography of chest which revealed "abrupt cut off of left main bronchus with emphysematous changes involving whole left lung parenchyma causing mediastinal shift to the right". On further evaluation, was advised for bronchoscopy by an otolaryngiologist expert in paediatric bronchoscopy.

After pre-operative work up patient taken up for bronchoscopy under general anesthesia and vegetative foreign body (pea nut of $0.8^{*} 0.6 \mathrm{~cm}$ ) was retrieved and procedure was uneventful. Patient recovered well in postoperative stay and stabilized with supportive care.

Manuscript received: $2^{\text {nd }}$ June 2017

Reviewed: $12^{\text {th }}$ June 2017

Author Corrected: $21^{\text {st }}$ June 2017

Accepted for Publication: $28^{\text {th }}$ June 2017 
Case Report

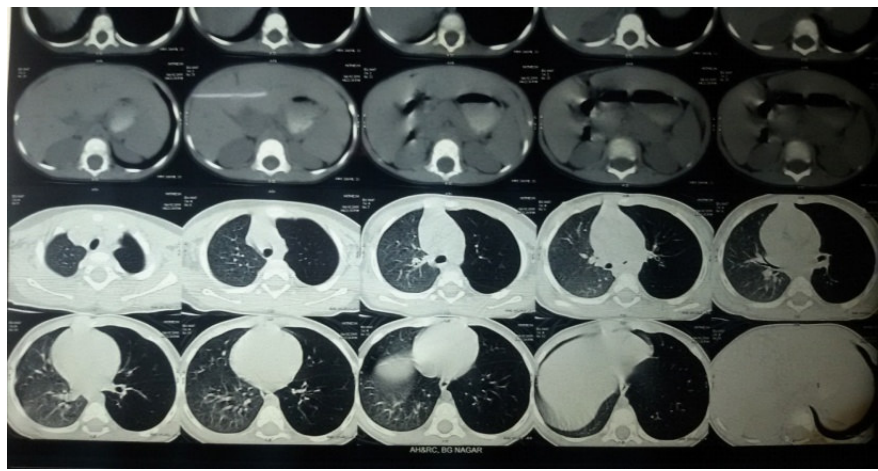

Fig 1: Abrupt cut off of left main bronchus with emphysematous changes involving whole left lung parenchyma causing mediastinal shift to the right

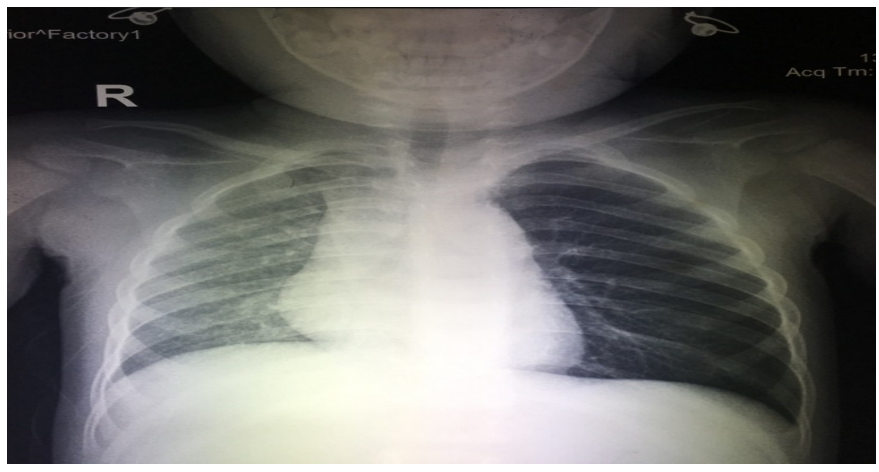

Fig 2: X-RAY showing left emphysematous lung with hyper inflated lung fields

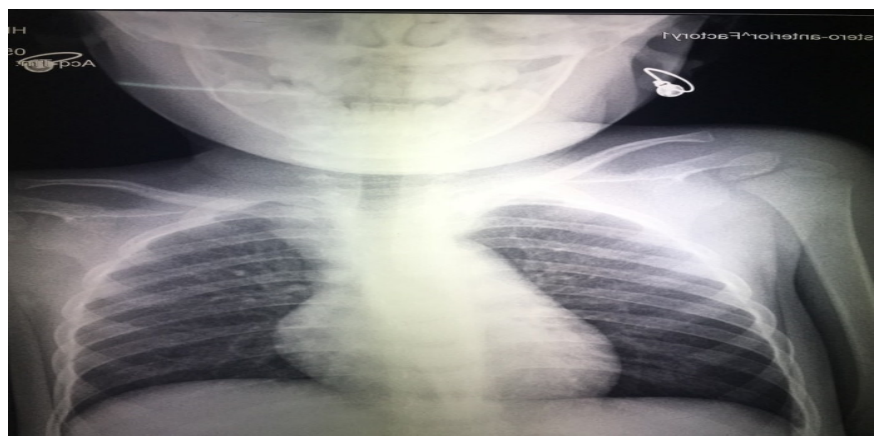

Fig 3: 2 weeks after post retrieval of foreign body showing normal lung fields

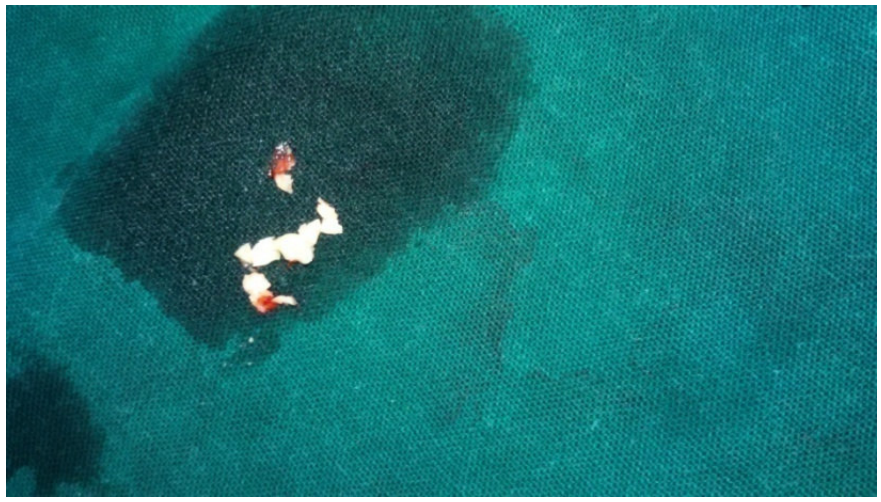

Fig 4: Retrieved pea nut from left bronchus 


\section{Discussion}

The majority of Foreign body aspiration occur in children younger than 3 years of age and boys being most common among them $[5,6]$. The tendency to introduce objects into the mouth, smaller diameter of their airway, activity while eating, immature dentition and having older siblings (who may place food or objects into the mouths of infants or toddlers) are the most common predisposing factors for Foreign body aspiration in children [1,7]. In older children, anatomic abnormalities and neurologic disorders predispose to Foreign body aspiration [8].

Food items such as peanuts, seeds, nuts, popcorn, beans, and corn are the most common item aspirated by infants and toddlers. Nonfood items such as coins, balloons, paper clips, pins, toy parts, needles, and pen caps more commonly are aspirated by older children [9]. Most of the objects aspirated by children are radiolucent, whereas only $18 \%$ to $20 \%$ of aspirated foreign bodies are radiopaque in nature $[7,9]$.

Younger children especially under 3 years, have considerable risk of foreign body aspiration as they have tendency of using their mouth to explore their surroundings and at this stage of development, the main objects aspirated are vegetable seeds, peanuts and toy parts. The type of the foreign body also depends on social, cultural and economic status and eating habits of the family $[9,10,11]$.

Foreign body aspiration can be easily diagnosed with a typical history of aspiration (such as acute onset of choking and coughing) and atelectasis or hyperlucency on chest radiography. Unusual and misleading cases especially without aspiration history present with asthma like symptoms such as wheeze, chronic cough and recurrent or persistent pulmonary infiltrations, bronchiectasis and atelectasis $[10,11,12]$ his is an example of misleading case, without aspiration history, presented with chronic cough and noisy breathing at night. Decreased air entry and hyper resonance on percussion is the predominant physical findings in our study.

\section{Conclusion}

The clinical presentation of unwitnessed foreign body aspiration may be subtle, and diagnosis requires careful review of the history, clinical assessment. Hence, children who presents with prolonged respiratory symptoms, especially at the age of 1-3 require a high index of suspicion, and should consider foreign body aspiration as one of the differential diagnosis.

Funding: Nil, Conflict of interest: None initiated, Perission from IRB: Yes

\section{References}

1. Tan HK, Brown K, McGill T, Kenna MA, Lund DP, Healy GB. Airway foreign bodies (FB): a 10year review. Int J Pediatr Otorhinolaryngol. 2000 Dec 1;56(2):91-9.

2. National Safety Council. Accident facts. Chicago, IL: National Safety Council, 1991:24.

3. Metrangolo S, Monetti C, Meneghini L, et al. Eight years' experience with foreign body aspiration in children: what is really important for a timely diagnosis? J Pediatr Surg1999;34:1229-31.

4. Steen KH, Zimmerman T. Tracheobronchial aspiration of foreign bodies in children: a study of 94 cases. Laryngoscope1990;100:525-30.

5. Sahin A, Meteroglu F, Eren S, Celik Y. Inhalation of foreign bodies in children: experience of 22 years. J Trauma Acute Care Surg. 2013 Feb; 74 (2):658-63. doi: 10.1097/TA.0b013e 3182 789520 .

6. Eren S, Balci AE, Dikici B, Doblan M, Eren MN. Foreign body aspiration in children: experience of 1160 cases. Ann Trop Paediatr. 2003 Mar; 23(1):31-7.

7. Digoy GP. Diagnosis and management of upper aerodigestive tract foreign bodies. Otolaryngol Clin North Am. 2008 Jun;41(3): 485-96, vii-viii. doi: 10.1016/j.otc.2008.01.013.

8. Holinger LD, Poznanovic SA. Foreign bodies of the airway and esophagus. In: Flint PW, Haughey $\mathrm{BH}$, Lund VJ, et al, eds. Cummings Otolaryngology: Head and Neck Surgery. Vol 3. 5th ed. Philadelphia, PA: Mosby Elsevier; 2010: 2935-2943. 
9. Karakoç F, Karadağ B, Akbenlioğlu C, Ersu R, Yildizeli B, Yüksel M, Dağli E. Foreign body aspiration: what is the outcome? Pediatr Pulmonol. 2002 Jul; 34(1):30-6.

10. Kiyan G, Gocmen B, Tugtepe H, Karakoc F, Dagli E, Dagli TE. Foreign body aspiration in children: The value of diagnostic criteria. Int J Ped Otorhinolaryngol. 2009, 73 (7): 963-967.
11. Tokar B, Ozkan R, Ilhan T: Tracheobronchial foreign bodies in children: importance of accurate history and plain chest radiography in delayed presentation. Clin Radiol. 2004, 59 (7): 609-615.

12. Karakoc F, Cakir E, Ersu R, Uyan ZS, Colak B, Karadag B, Kiyan G, Dagli T, Dagli E. Late diagnosis of foreign body aspiration in children with chronic respiratory symptoms. Int J Pediatr Otorhinolaryngol. 2007 Feb;71(2):241-6. Epub 2006 Nov 27.

\section{How to cite this article?}

Balaji.M.D, Venkatamurthy M, Naresh S. An incidental finding of a vegetative foreign body in left main bronchus in a child presented as wheeze associated respiratory tract infection. J PediatrRes.2017;4(06):357360.doi:10.17511/ijpr.2017.i06.01. 